Dena Fam, Abby Lopes, Juliet Willetts, Cynthia Mitchell

Despite the obvious health benefits of the sanitary revolution and construction of sewered systems, there are increasing doubts about the long term sustainability of centralised, water-based sanitation. Growing uncertainties such as rapid population growth,
emergence of new pollutants, changing hydrological conditions in relation to climate change and global economic instability will require systems to be more open to 'flexible and reflexive approaches''1] in meeting future sanitation needs. The highly inflexibite nature of existing sanitation systems burdened with over a century of capital infrastructure investment and assets that require $30-50$ years to pay back, make centralised sanitation both economically unsustainable and institutionally rigid. Social practices
associated with water-borne sanitation have been embedded within western society for over a century making 'radical' system change and the introduction of alternative technologies and habits of practice challenging. Change therefore cannot be brought abo
through technological innovations alone; it requires mutually reinforcing institutional and socio-cultural transformations. [2] This has important implications for the relation between design and technological innovation. Design can be understood as a practice through technological innovations alone; it requires mutually reinforcing institutional and socio-cultural transformations.[2] This has important implications for the relation between design
involving the deliberate planning of socio-technical change, yet the relational dynamics of change have not traditionally played a part in design biased toward a technological fix'.[3]

Analysing the historical development of water-borne sanitation in Sydney in the mid nineteenth century is one way of gaining insights into potential challenges for a transition towards more sustainable sanitation options. By highlighting the co-evolution of technology and society where novel technologies, institutions, associations and user practices have emerged out of processes of socio-technical alignment, an analysis of how system change has occurred in the past provides useful insights into how more

There is also much to gain in analysing the relationship between society, social ideals and changing concepts of cleanliness in the mid nineteenth century on the one hand and technological innovation on the other. Even though social behaviours and cultural norms of the mid nineteenth century have changed significantly in relation to contemporary society, a historical analysis of socio-technical change provides a means of reflecting on past transitions not just in relation to technology but also society. The complexity of system innovation raises the benchmark for design's contribution to the transition to more sustainable socio-technical systems. Design must go well beyond the traditional focus of product-oriented, market-driven, technical efficiency
which produces finite 'solutions' to complex multi-faceted problems. These solutions tend to be based on obvious technical performance criteria such as an operational reduction in water reguirements, but more often than not the design is discoinnected from

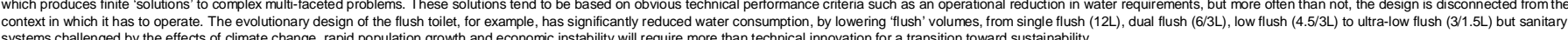

The development of water-borne sanitation in many western countries, including Australia, occurred within the Victorian era which, according to Thomas and Ford, [4] was characterised by a culture of technical innovation of highly engineered, linear, "end of pipe' solutions to the problem of wastewater management. There is little doubt that the development of ceelly

The transformation of sanitation from the use of cesspools[5] to sewer systems was a radical change and can be characterised as a transition[6] whereby both the technical and socio-cultural dimensions of the system changed drastically. In the transition, society and technology became highly interrelated, forming what has been described as a 'seamless web' of mutual dependency. [7] The contemporary implications of this early socio-technical transformation of society suggest that any deliberate
change toward a system of sustainable sanitation will require a nuanced understanding of both the social and technical dimensions that contribute to change Rip and Kemp's multi-level model of innovation is regarded as useful in analysing historical transitions in socio-technical systems. It views socio-technical transitions as interactive processes of change that occur
the co-evolution of technology and society occurs. At the core of the multi-level framework is the dynamic concept of the socio-technical regime (meso level). Rip and Kemp explain a technological regime as:

the rule set or grammar embedded in a complex of engineering practices, production process technologies, product characteristics, skills and procedures, ways of handling relevant artefacts and persons, ways of defining problems: all of them embedded within institutions and infrastructures' $[9]$

This definition suggests that rules are embedded in human actors, technical systems and artefacts which enforce stability and path dependency in the technological regime. This description of a regime helps to explain why most technological change is incremental rather than radical

Complementary to the regime and implicated in socio-technical change is the niche (micro level) in which human actors experiment with radical innovation in a protected environment. New technologies, product development and user practices emerge at
lo level and are radically different from mainstream practices and technologies. The broader landscape (macro-level) represents slow changing factors such as socio-cultural norms, political coalitions, long term economic developments and accumulated the micro level and are radically different from mainstream practices and technologies. The broader landscape (macro-level) represents slow changing factors such as socio-cultural norms, political coalitions, long term economic developments and accumulated
environmental problems' $[10]$ that may take generations to change under stable conditions. Sudden crises such as climate change, wars or fuel shortages may change the landscape quickly and create opportunities for innovation across multiple levels. This environmental problems' [10] that may take generations to change under stable conditions. Sudden crises such as climate change, wars or fuel shortages may change the landscape quickly and create opportunities for innovation across multiple levels. This
multi-level model has been proven to be useful for contextualizing spatial and historical factors in socio-technical change[ 111$]$. A number of historical case studies of socio-technical change have been analysed using this model, including transitions in energy, $[12]$ aviation,[13] waste management[14] and personal hygiene.[15]

This basic explanation of how socio-technical systems change is interesting to consider in regard to design's potential for contributing to a transition toward sustainability. While design might identify with the regime level characterisation presented above, it could also be understood as operating across these levels, particularly in terms of the co-evolution of artefacts and human practices.[16] This has implications for how design may conceive of its sphere of influence. In relation to the multi-level studies have shown that new technologies designed for specific markets are generally variations of existing technologies which require little change in habits of behaviour and utilise existing infrastructures. This approach to design therefore contributes to path dependency and 'lock-in' of existing systems, making the introduction of technological alternatives to the norm challenging. The disincentive of system innovation or radical transformation of society and technology is that the benefits of system change have historically occurred over a much longer timeframe (25 years or a generation) than a quick 'technological fix' (potentially
5 years). There is debate as to whether factor 10 efficiencies [17] can be achieved in much shorter time frames if design is understood in relation to a socio-technical framework. However there are examples which suggest that appropriate, contextually-relevant
design may contribute to accelerated change. For example the European bike share scheme Vélo' $v$, which began in Lyon, France in 2005 is a deliberate system design integrating a network of people, products, services and infrastructures that is characterised by what Ezio Manzini has characterised as 'Iow material-energy intensity' but a 'high degree of context quality':[18] The end-user has access to an open and flexible system which consists of robust and comtortable bikes, a dense network of bike stations installed across the city and surrounding suburbs with all trips under half an hour available for free. Bike tracking and diagnostics are managed by sophisticated information technology which remotely checks that bikes are functioning optimally. The system has been
highly successful in realising bike share as a legitimate and contextually appropriate alternative to cars for short urban trips with each bike shared by 7 and 15 people a day. [19] The success of this product service system (PSS) led to the launch of 'Vélib' bike

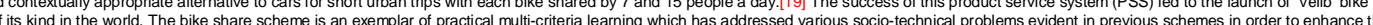
competency of the system to meet future demands.[20]

For design to achieve its potential for contributing to a transition toward sustainability, requires reconsideration of design as fundamentally social and 'made of' people and practises as much as it is 'made of technologies, artefacts and Infrastructures.[21] 'Radical change' in a system toward sustainability requires innovation across social, cultural, institutional and technological domains which are relationally co-dependent. As we shall soon see, it was not the emergence of a "technological fix
that drove system innovation in sanitation in Sydney in the mid nineteenth century; technological innovation was mutually supported and reinforced by factors such as rules and regulations, an alignment with changing social practices, cultural values and beliefs about the technology and system. For transitions to occur the regime needs to be open or adaptable enough to accept radical innovations; transition happens when there is pressure from the landscape for change and when radical innovations have emerged $n$ niche environments to take advantage of the opportunities for change. The multi-level perspective (MLP) therefore offers design a strategic analytical tool for reflecting on the complexity of systems, temporality of change and importantly the 'social' nature of

It becomes obvious when considering the MLP, that slow moving factors located at the landscape (macro level) such as economic crisis and effects of climate change are resistant to efforts to radically change them. Whereas the regime (meso level) can cope well with incremental changes in technology, designers have limited influence in changing the set of rules that guide technological innovation along a particular trajectory. Where designers have the most influence in creating change toward sustainability is

列

With this is mind, let us return to the origins of centralised water-borne sanitation in mid nineteenth century Sydney and consider how multi-level developments were implicated in the transition from the use of cesspools to sewer systems. In the past there have been a number of historical transitions in socio-technical systems driven by 'crises' at the macro level. The 'sanitary revolution' of the mid nineteenth century was in part driven by the widespread outbreak of dysentery (macro level) destabilising existing practices and leading to regulatory reform (at the meso level) which stimulated innovation in wastewater management (at the micro-level). Transtorma
housing, behavioural changes in washing and bathing, policy changes making voting more inclusive and cultural changes in everyday practices. [23]

Analysing the transition from a niche perspective highlights the fact that niche developments first emerged in the protected arena of the upper class, where reticulated water supply became available in 1844[24] to a minority of households which could afford the connection to piped water. Water closets[25] although rare in Sydney during this time, were emerging in mansions of the upp
overflowed from cesspools, leaking into ground water and flowing into water sources increasing incidents of water-borne disease.[26]

Niche developments were not only associated with technical innovation during this time but also new everyday practices. The Victorian social doctrine, that physical well-being and a clean environment were connected to social progress, fuelled the
movement in Britain, subsequently in Sydney and many other industrialised cities of the world. Sanitary reformers in the United States had similar beliefs about tinsanitary conditions and its connection to moral degradation. [27] Athough these beliefs macro-social developments, when they were coupled with greater access to piped water, the beliefs created new practices of cleanliness (originally in the protected environment of the upper class) which led to a reconfiguration of social ideals. The adoplifs. diffusion of the water closet and adjoining sewer systems are inseparably connected to perceptions of cleanliness. When cleanliness became linked to the prevention of epidemics, "dirtiness became the problem in the city and cleanliness was the solution."[28] Technical infrastructures and artefacts such as sewers, piped water and the water closet were seen as the means to solve the problem. The very emergence of these niche developments were related to global changes on a macro level where the industrial
revolution and insanitary conditions of the lower class divided the population into 'clean and dirty', high and low' and 'rich and poor'. [29] New behavioural patterns in relation to cleanliness emerged within the protected sphere of the wealthy; therefore social revolution and insanitary conditions of the lower class divided the population into 'clean and dirty', 'high and low' and 'rich and poor'. [29] New behavioural patterns in relation to cleanliness emerged within the protected sphere of the wealthy; therefore soc
habits of 'washing, scrubbing and flushing' emphasised the distinction between the upper class and the unwashed lower class. With the widespread availability of piped water and a greater understanding of the connection between washing and disease
prevention, the niche practices of the upper class became more widely accepted and diffused throughout all classes of society The 'sanitary revolution' was preceded by a number of political revolutions and upheavals fuelled by the social impacts of industrialisation. From a macro level perspective, many industrialised cities of the Victorian era experienced similar global drivers in
the adoption of a centralised sewer system. Industrialisation in particular was a global phenomenon which led to rapid population growth and crowded, insanitary living conditions.

Macro-environmental perspective
From a biophysical perspective Sydney, in particular, had contextual macro-drivers specific to the region. Highly erratic annual rainfall and sudden, lengthy and severe droughts, unheard of in the experience of British immigrants, made it necessary for the city to store more water per head of population than any other major city in the world. [30] The struggle to tame the environment' in the face of a rapidly growing population and variable climatic conditions has been a recurring theme throughout Australia's history.

Macro-political perspective

From a macro-political perspective, Sydney was a changing colony. Founded in 1788 with a population of 1000 settlers, by 1850 colonial politics had already shifted from a deferential-authoritarian style government which was suitably required for the newly
formed colony with a high population of convicts, to a democratic populist style government with a demographic that now wincluded a higher percentage of free settlers.[31] Athough Sydney Council was 'democratic' by 1840 , it was still characterised by a libera formed colony with a high population of convicts, to a democratic populist style government with a demographic that now included a higher percentage of free settlers.[31] Athough Sydney Council was 'democratic' by 1840 , it was still characterised by a liberal political ideology and an economic policy influenced by the wealthy, aimed at minimising effects on businessmen.[32] For example, it was only the wealthy landowners that had the right to vote[33] and as they were advocates of low taxes, funding for public
infrastructural projects such as centralised sanitation was resisted. Beder notes that one of the major setbacks of constructing a central sewer system in Sydney was the middle class refusal to pay higher taxes to fund its development. [34] There was little
incentive for the wealthy to pay for sewerage as they lived in spacious conditions beyond the city centre and were not directly affected by insanitary conditions, unlike the poor who bore the consequences of overcrowded living conditions. [35] "Those who paid incentive for the wealthy to pay for sewerage as they lived in spacious conditions beyond the city centre and were not directly affected
the most rates had the least to gain from public expenditure on sanitation. Those who suffered the most had the least to say":[36]

\title{
Macro-economic perspective
}

A number of significant events took place in Sydney between $1850-1890$, that influenced the government's decision to eventually finance and construct a large scale centralised sanitation system. From a macro-economic perspective, the discovery of gold at
Bathurst 150 miles west of Sydney [37] created new found wealth and the subsequent development of new industries in Sydney which brought greater confidence to the colony. The expected increase in Sydney's population with the discovery of gold created a Bathurst 150 miles west of Sydney[37] created new found wealth and the subsequent development of new industries in Sydney which brought greater confidence to the colony. The expected increase in Sydney's population with the discovery of gold created a willingness to plan a sewerage scheme for accessible parts of Sydney and commit capital for its completion. The Water and Sanitation Act (1853) authorised finance for the construction of sewers. Consequently there was a substantial growth in Sydney's water
and sewerage services and by the 1880 's the city was fully serviced with piped water. This became an additional driver for underground sewers as large volumes of wastewater were being generated without means of disposal, making the sanitation problem. and sewerage services and by the 1880 's the city was fully serviced with piped water. This became an additional
worse. It wasn't until the 1890 's that Sydney was both fully serviced by piped water as well as fully sewered.[38]

Co-ordination of the medical regime in system change

By the time the social, economic and technological developments began driving improvements in sanitation, the dominant medical belief of 'Miasma Theory' was already influencing perceptions of how sewerage systems should be developed. According to

Before the 1880 's, foul smells or 'miasmas' were believed to be the cause of illness. It wasn't until the cholera epidemic in London 1853-1854, that John Snow, a British hygienist proposed the 'germ theory' and that cholera was spread through drinking
Bef water contaminated by feces from cholera patients. [40] By 1883, scientist Robert Koch confirmed the beliefs of many sanitary reformers by isolating the germ for cholera under the microscope. But it would take a number of decades before 'germ theory' would

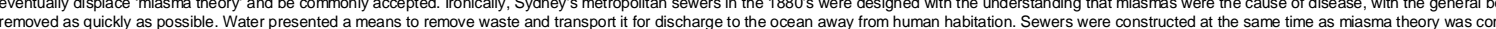
removed as quickly as possible. Water presented a means to remove waste and transport it for discharge to the ocean away from human habitation. Sewers were constructed at the same time as miasma theory was coming under scrutiny from new scientific
evidence on 'germs'. Therefore, the timing of contextual factors, such as the belief in miasma theory, was influential in the outcome of the sanitary revolutiton and the technologies adopted This reveals the significance of developing a historical perspective on the
evolution of slow moving, large technical systems such as sanitation. Contextual factors and beliefs (such as miasma theory) have contributed to embedding centralised technology, infrastructure and social practices within western society even though these beliefs and understandings may be irrelevant and out-dated by today's standards. Sydney, as many other developed cities in the $21^{\text {st }}$ century, has inherited a system of sanitation that has been designed for the past yet must deal with an uncertain future. It is this
sort of insight that a MLP makes available.

\section{Macro-political developments}

By 1865,1300 households were connected to the sewers which discharged into various parts of the harbour. The large volume of sewage led Sydney's smelly bays to be branded as "immense cesspools" $[41]$ affecting not only the biophysical health of the
harbour but also believed to be the cause of Scarlet Fever and Measles epidemics. The pressure to change the existing sewerage system was strong, with 3800 petitioners asserting that the foul state of the port would deter immigration and trade to the city.[4 2

The Sewerage and Health Board had set up two different outfall schemes. [43] The Northern System with ouffall to the ocean at Bondi would intercept the northern sewers draining sewage without treatment into the harbour, and the Southern System with outfall to a sewerage farm at Botany Bay would drain suburbs south of the city. The choice of these treatment methods reflected the two main ideas shaping the contemporary international debate on sewerage treatment: firstly, that sewage was dangerous

The Botany Bay sewerage farm scheme was experimental and was cheaper than constructing sewers for ocean disposal in the short term[45] and if it failed the sewers could be extended to the ocean at a later date. Approximately 10 years after the
anent of the Botany Bay sewerage farm, the Royal Commission into Melbourne's public health, also accepted a proposal for a sewage farm that still exists today and treats approximately $52 \%$ of Melbourne's sewage (485 million litres a day). The sewerage farm at Botany treated wastewater with 'downward filtration' where the soil acted as a filter through which the sewage drained and where crops could be grown in soil enriched by the application of sewage. In 1889,309 acres of land was obtained by the

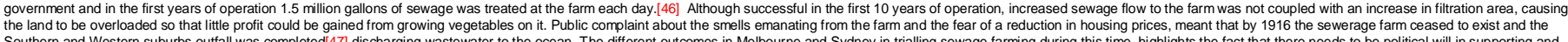

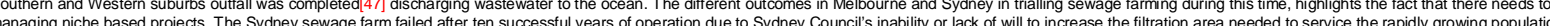


Summary and implications for design practice

Approaching transition toward sustainability through the design of technical artefacts alone may offer some improvements in efficiency but does not contribute to the radical transformation in the water sector which is required in the face of the challenges associated with climate change. The urban sanitation system that exists in Sydney today (and many other global cities) emerged over time to consist of a conglomerate of interconnected components such as technological artefacts, markets, user practices, rules The relationship between a multitude of factors (social, political, economic, environmental, technological) has supported a stable system of practice that has been subject to incremental changes in the system ever since its inception. Athough there is little doubt that the development of a centralised sactation system has greatly benefited public health over the last century, the challenges of an uncertain future with greater risks from new pollutants and contagious diseases, a rapidly growing population and variable hydrological conditions associated with climate change raises doubts about the ability of the existing system to deal with such uncertainties.

Design (including all of its 'green' versions) which is so deeply invested in improving the efficiency of existing systems, has much to learn from specific historical examples of transformation as has been discussed in this paper. As suggested earlier, this perspective redefines design's sphere of influence as it reveals the dynamic complexity of socio-technical change (as well as its biophysical impacts). If design is to contribute to system innovation in large scale technical systems such as wastewater management, taking a socio-technical approach is required in order to grasp the interplay of factors that contribute to the persistence of the existing system. By emphasising the importance of 'technology' alone in transition, the socio-technical environment in which the technology is used is underestimated and the required regulatory and institutional adaptation is ignored inhibiting the sorts of socio-technical transformations that are now required in the face of future uncertainties. Such an approach implies a differen
conduct of design in response to climate change imperatives - one that is more oriented to practical learning than technological fix.

In closing, let us regard a relevant artefact: the flush toilet. In considering a transition from centralised, end-of-pipe solutions toward more sustainable sanitation options, redesigning the artefact or flush toilet only solves a small part of the problem. The 'flush toilet' is not an isolated artefact but part of a much broader socio-technical system comprising of sewerage pipes, waste water treatment plants, water supply, extensive capital inirastructure investment, rules and regulations dictating health standards on

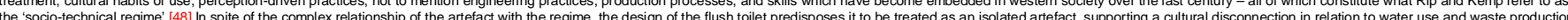
Therefore if design is to influence shifts in the socio-technical regime towards sustainability, then learning how alternative more sustainable technologies are adopted and supported is an important part of the design process. If as Rohracher [49] argues, echnological change is inherently social, then it would make sense for designers to consider how alternative forms of sanitation play out within a specific social context. Trialling and experimenting with an innovation in use provides opportunities to find points of intervention that could resonate across a multitude of areas (social, technological, economic, environmental and political). This has been a rapidly growing area of research[50] and has the potential to offer design a means to contribute to sustainability beyond he traditional focus of technical, finite solutions to complex problems and in the process, perhaps learn to transform its own nature.

Dena Fam is a PhD student and research assistant at the Institute of Sustainable Futures, University of Technology Sydney, with a Bachelor of Industrial Design from University of Westem Sydney. Her PhD research is on how sanitation systems - understood as complex relationships between materid infrastructures, resources, social actors, nules and regulations - should be designed (in the broadest sense) to contribute to sustainability in wastewater management

Abby Lopes is a Lecturer in Design Theory in the School of Communication Arts (and formerly in the School of Engineering) at University of Western Sydney. She has a PhD from the University of Sydney and a background in design and cultural theory and design for sustainability. Her current research interests are in irigation futures for urban public space, image ecologies and future scenario planning.

Cynthia Mitchell is Professor of Sustainability at UTS' Institute for Sustainable Futures. She has a PhD from the University of New South Wales, an Honorary Doctorate Technology from Chalmers, Sweden, and is an Australian Leaming and Teaching Council Fellow. Her practice-led work for change is

Juliet Willetts is a Research Director a he institute of Sustainable Futures, University of Technology Sydney where she leads consultancy research to influence policy and practice in sustainable water management and sanitation and in international development aid. She has a PhD from the University of NSW in Environmental Engineering

[1] T.A. Larsen and W. Gujer, 'Waste design and source control lead to flexibility in wastewater management' Water Science Technology, 43(5), 2001, p. 309-318.

[2] F. Geels, 'Processes and patterns in transitions and systems innovations: refining the co-evolutionary perspective' Technological Forecasting and Social Change, 2005. p. 72.

[3] A. Borgmann, Technology and the Character of Contemporary Life: A Philosophical Inquiry, University of Chicago Press, 1984.

[4] D. Thomas and R.R. Ford, The Crisis of Innovation in Water and Wastenater, Cheltenham, UK: Edward Elgar, 2005

[5] Cesspools were part of a system of innovation in which large holes were dug in residents' backyards into which wastewater from toilets was discharged.

[6] Loosely defined a transition “... denotes a long term change in an encompassing system that serves a basic societal function." The emphasis on the co-evolution of techrical and societal change distinguishes transitions from incremental change which is primarily characterized by technical change with relatively little atteration of the social habits associated with these technologies. B. Elzen and A. Wieczorek, 'Transition toward sustainability through system innovation' Technological Forecasting and Social Change, 2005 . p. 72.

[7] bid.

[8] 'The levels in the model are not ontological descriptions of reality, but analyical and heuristic concepts designed to understand the complex dynamics of socio-technical change'. F. Geels, 'Technological transitions as evolutionary reconfiguration processes: a multi-level perspective and a case stud Research Policy, 31, 2002, pp. 1257-1274

[9] A. Rip and R. Kemp, 'Technological change' in Human Choice and Climate Change. Colombus, OH: Batelle Press, 1998, p. 340 .

[10] bid.

[11] J. Mackard and B. Truffer, 'Technological imovation systems and the mutti-level perspective: towards an integrated network' Research Policy, 37, 2008, pp. 596-615.

[12] G. Verbong, and F. Geels, 'The ongoing energy transition: lessons from a multilievel analysis of the Dutch electricity system (1960-2004)' Energy Policy, 35(2), 2007, pp. 1025-1037.

[13] F. Geels, 'Co-evolutionary and multi-level dynamics in transitions: the transformation of aviation systems and the shift trom propellor to turbojet (1930-1970)' Technovation, 26, 2006, pp. 999-1016.

[14] S. Parto et al., 'Transition and institutional change: the case of the Dutch waste subsystem' in Industrial innovation and environmental regulation, S. Parto, (ed.) New York: United Nations University Press, 2005.

15] F.W. Geels, 'The hygienic transition from cesspools to sewer systems (1840-1930): the dynamics of regime transtormation' Research Policy. 35, 2006, pp. 1069-1082.

[16] E. Shove et al., The Design of Everyday Life, Oxtord, UK: Berg, 2007

[17] Friedrich Schmidt-Bleek from the Wuppertal Institute proposed the need for a Factor 10 reduction in the resource intensity of products and services, and the MIPS (Material intensity per Unit Service) tool to help bring these reductions into being. See Friedrich Schmidt-Bleek 'The Factor 10MMPS. Concept: Bridging Ecological, Economic, and Social Dimensions with Sustainability Indicators', UNUUZEF Discussion Paper Series 2, The United Nations University, Zero Emmissions Forum, 1999. Available online: http///wmw.unueduzetppublications-e/ZEF-EN-1999-03-D.pdf [Accessed 4th March

[18] E. Manzini, 'Scenarios of sustainable well-being' Design Philosophy Papers, 2003(11.

19] Statistics from Velib press release: www.paris.tr/portail/viewPDFile Serviet?file id=16272.

[20] url: unww.velov. grandlyon.com/ [Accessed 10th January 2009]

See also url : htp://uk.franceguide.com/press/Velib-Paris-new-bike-transit system.hthm?node ID=4228EditolD=88863 [Accessed 10th January 2009]

[21] Shove, op cit.

22] Strategic Niche Management (SNM) is an approach in transition management that advocates the strategic creation of niches or protected spaces where new technologies have the opportunity to mature through 'gradual experimentation and learning by actor networks of producers, researche users, govermmental and other organizations'. M. Caniels and H. Romijin, 'Strategic Niche Management as an operational tool for sustainable innovation: guidelines for practice' in Working paper 06/07, Centre for Innovation Studies, University of Eindhoven: The Netherlands, 2007, p. 18. [23] An in depth analysis of the transition from cesspools to sewer systems in the Netherlands was conducted by F. W. Geels using MLP in 'The hygienic transition from cesspools to sewer systems (1840-1930): The dynamics of regime transformation' Research Policy, 35, 2006, pp. 1069-1082. [24] W.V. Aird, The Water Supply, Senerage and Drainage of Sydney, Kingsgrove, NSW: Halstead Press, 1961.

[25] The water closet was a term for flushing toilets and aptly named as they were installed in small 'closel' sized rooms in the home.

[26] D.H. Coward, Out of sight: Sydney'senvironmental history 1851-1981, Canberra: ANU printing and duplicating, 1988.

[27] J.A Tarr, 'Sewerage and the development of the networked city in the United States, 1850-1930' in Technology and the rise of the networked city in Europe and America, ed. J.A. Tarr and G. Dupuy, Temple University Press: Philadelphia, 1988, pp. 159-185.

281 M-B. Quitzau, 'Changing ideas of bodily cleanliness' in 6 th International Summer Academy on Technology Studies. Urban Infrastructure in Transition: What can we leam from history? Deutschlandsberg. Austria, 2004.

[29] F. W. Geels, 'Co-evolution of technology and society: The transition in water supply and personal hygiene in the Netherlands (1850-1930) - a case study in multil-evel perspective' Technology in Societty, 2005. p. 27.

[30] Aird, op cit

[31]Coward, op cit

32] Aird, op cit: Coward, op cit; S. Beder. 'From Pipe Dreams to Tunnel Vision: Engineering Decision-Making and Sydney's Sewerage System' in Engineering, University of NSW, 1989; A.J.C Mayne, Fever, squalor and vice: sanitation and social policy in Victorian Sydney, St Lucia: University of Queensland Press, 1982, p. 261.

[33] Coward, op cil

[34] Beder, op cit

[35] bid.

[36] bid.

[37]Coward, op cil

[38] bid.

39] A. Corbin, The foul and the fragrant: odour and the social imagination, London: Macmillan, 1996, p. 305.

[40] Mayne, op cit.

411] Coward, op cit.

[42] bid.

[43] bid.

[44] Coward, op cit and Beder op cit.

[45] bid.

[46] Aird, op cit.

[47] Coward, op cit. and Beder, op cit

[48] Rip and Kemp, op cit.

[49] H. Rohracher, The mutual shaping of design and use: innovations for sustainable buildings as a process of social learning. 2006, Munchen, Wien: Profil.

50] Research on Strategic Niche Management has been growing rapidly in Europe and has culminated in the documentation of a number of transition experiments. An in-depth analysis of this research is beyond the scope of this paper but is i mportant to mention as a framework in which design has the potential to contribute to sustainability beyond technical efficiency. See C.Vezzoli, F. Ceschin and R. Kemp, 'Designing transition paths for the diffusion of sustainable system innovations in Changing the Change, Torino, thaly, 2008. 